\title{
Reflections on my studies of the effects of sulphonamide drugs in bacillary dysentery in Egypt, 1943-1944
}

\author{
J G Scadding (1907-1999)
}

J R Soc Med 2006;99:423-426

Additional material for this article is available from the James Lind Library website [http://www.jameslindlibrary.org] where this paper was previously published.

This is an attempt to recall and set down briefly my recollections of the studies of the use of sulphonamides in bacillary dysentery which I made in 1943 and 1944 during my service in the Royal Army Medical Corps in Egypt. ${ }^{1-3}$ I end with a note on the relevance of this experience to my membership of the MRC Streptomycin Trials Committee in 1946 onwards.

I will start by outlining my background at the time of the dysentery studies. I had been in Egypt for 3 years at the time of the studies. I was officer-in-charge of the medical division of the 19th British General Hospital, situated at Fayid, on the shore of the Great Bitter Lake (which lies in the course of the Suez Canal), half-way between Port Said and Suez. The responsibilities of this posting can be compared with those of a combined administrative and clinical director of a department of medicine (including all specialties) in a large general hospital. We were probably the largest British military hospital in Egypt, with 1800 beds for British and allied troops, and 1000 for German prisoners of war. We were at the centre of a large number of base units, not only army, but also air force and navy.

Sited as we were in the desert, miles away from Cairo, Alexandria or other large towns, we were left to get on with our job of dealing with the medical problems of a large and changing population of troops from all over the world, with very little interference from 'higher-ups'. In addition to myself as officer-in-charge, the medical division consisted of two medical specialists and a limited number of general duty officers; usually about three, but reduced in the very busy summer of 1943 to one-and-a-half, one being shared with the surgical division. Our division would typically have to deal with 700 or even more patients at any one time, all acute admissions.

I was required to produce quarterly reports of the activities of my medical division, and have preserved copies of them. Looking at the reports for the periods in 1943 and

Text of a manuscript sent to lain Chalmers in June 1999 for publication in the James Lind Library
1944 in which I did the 'sulphonamides in bacillary dysentery' studies, I find that in the 3 months July to September 1943 we had 486 cases of dysentery among a total of 3509 admissions. In 1944 there were 590 cases among 3774 admissions. This indicates the background of heavy clinical responsibilities with which any attempt at scientific investigation was competing. At one time or another we had to deal with nearly every acute infectious disease then known. The only notable exceptions were yellow fever and cholera, which did not occur in our area. Small-pox and plague appeared occasionally, as did outbreaks and sporadic cases of enteric fevers (typhoid and paratyphoid) and diphtheria. Occasional outbreaks of the infectious diseases then prevalent in childhood in the West (measles, rubella, chicken pox, etc.) occurred among troops coming in from other areas, notably Ceylon.

The story of sulphonamides in the treatment of bacillary dysentery, as I saw it, seems in retrospect to be a good illustration of the way in which the introduction into practice of a therapeutic procedure on the basis of a priori theoretical considerations, without a proper clinical trial, may lead to entrenched 'clinical impressions' that are both erroneous and difficult to displace.

When I arrived in Egypt in May 1941, my experience had been in general medicine with a special interest in

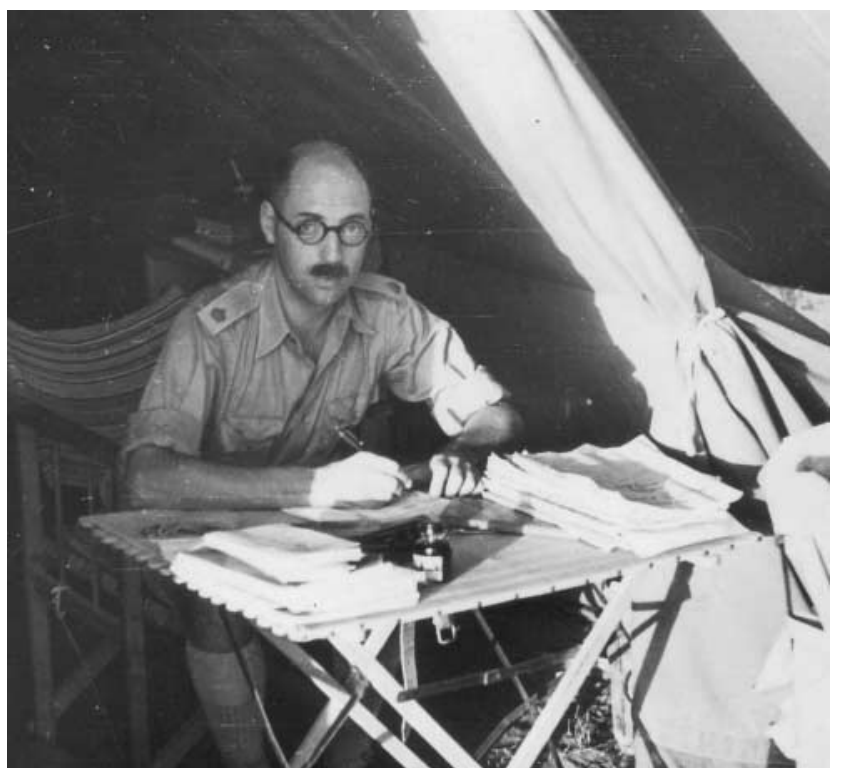


respiratory disease, with little or no experience of diseases prevalent in tropical areas. In February 1941 I had attended a course on tropical diseases in Liverpool, which, as one who had myself been concerned with postgraduate medical education, I thought of high quality; but I can recall no mention during the course of the possible use of sulphonamides in dysentery. Sulphonamides had been in clinical use for no more than 5 years. Sulphanilamide, the first sulphonamide generally available, had been found really effective only against haemolytic streptococcal infections, notably puerperal fever. The first sulphonamide with wider antibacterial activity, sulphapyridine (M\&B 693) had become available about 1937-1938.

At that time, pneumococcal lobar pneumonia was an important cause of death in previously healthy young people, and I had been concerned in attempts to assess the value of a recently introduced anti-pneumococcal serum prepared in rabbits in this disease (sera prepared from horses had been widely investigated with equivocal results, and had been largely abandoned because of the frequency of serum reactions). The lack of any immediately obvious effects of the anti-pneumococcal serum on the course of pneumococcal lobar pneumonia, with the consequent difficulty of designing a study in which any small difference might be demonstrated, contrasted with the obvious effect of sulphapyridine in such cases. This led us to abandon the study of the serum treatment and the adoption of sulphapyridine as the accepted treatment for pneumonia of this bacterial type.

Bacillary dysentery was among the most frequent diseases we had to deal with in Egypt. Its severity varied widely (from many mild infections to some that were very severe and dangerous), and it was attributable to a wide range of bacterial varieties. When I arrived, the standard treatment was, in effect, supportive care with fluids only. Some probably harmful procedures were still sometimes advocated; for instance, there was even a residue of the idea that saline purgation ought to be helpful by ridding the bowel of the infective agent. I cannot remember when or in what form the official recommendation of sulphaguanidine as a more or less 'specific' treatment for bacillary dysentery appeared. The general message was that sulphaguanidine was the drug of choice for the treatment of bacillary dysentery because it was poorly absorbed, persisted in high concentration in the large gut (where it was active against coliform organisms), and was almost free from the sorts of unfavourable systemic effects on the blood, bone-marrow and kidneys that the absorbed sulphonamides might cause.

Initially, however, sulphaguanidine was in short supply, and it therefore had to be reserved for severe cases of bacillary dysentery. The result was predictable: even those of us who retained our critical faculties but nevertheless prescribed sulphaguanidine for a man with severe dysentery, to attribute a favourable course of the disease to the sulphaguanidine. And if the patient died, we wondered whether he might have recovered if the drug had been given earlier in the course of the disease. Accordingly, when sufficient supplies of sulphaguanidine became available, it became established as the standard, reputedly 'specific', drug for bacillary dysentery.

Several people are on record as having doubted this dogma, claiming that absorbable sulphonamides (sulphapyridine, sulphathiazole) and even the simple sulphanilamide (see citations in reference 1) were at least as effective as sulphaguanidine. There is a note in my report for AprilJune 1944:

'Capt. Schwartzman who has been in charge of the African section, has been using various sulphonamide drugs in the treatment of bacillary type dysentery, and has concluded that sulphapyridine gives a prompter response than sulphaguanidine and is well tolerated by African troops'.

\section{THE SULPHONAMIDE TRIALS}

During the extremely busy summer of 1943, supplies of sulphaguanidine again became restricted, so that once again it was reserved for severe cases. As the bacillary dysenteries prevalent in our area were on the whole of a relatively mild type, I took advantage of the opportunity to observe the effect of the most elementary sulphonamide - sulphanilamide - in a series of cases of bacillary dysentery in the officers' ward, for which I was solely responsible, as reported in my 1944 paper. ${ }^{1}$ The course of these cases was so similar to that expected in those treated with sulphaguanidine that I thought it justifiable to organize in the main hospital a double-blind comparative study in which 274 patients, in rotation, were allocated either to sulphaguanidine - the 'accepted' poorly absorbed drug or to one of two well absorbed sulphonamidessulphanilamide and sulphapyridine. Blinding was effected by supplying the three drugs in indistinguishable suspensions, lettered A, B, and C. The conclusions of the 1944 paper were largely sceptical; the differences between the therapeutic effects of the three drugs were very small, though sulphaguanidine had the advantage of fewer unpleasant side-effects, especially the renal effects likely to arise in a dehydrating disease in a tropical climate. The evidence of benefit in the mild type of disease prevalent in the area was equivocal, and benefit might be confined to cases caused only by some bacterial types. ${ }^{1}$ The studies done the following year (1944) are reported in my 1945 paper. $^{2}$ They started with a comparison of sulphaguanidine with succinyl-sulphathiazole, then recently introduced, which 
was even less absorbed than sulphaguanidine, only $5 \%$ being excreted in the urine. This study was not formally randomized, though effectively 'double-blind', alternate cases being treated with suspensions of the two drugs. As both were reputedly active, there was no reason to expect any preconceived bias in favour of either one of them. The course of the disease in the two groups was indistinguishable. Next, I carried out a similarly designed comparison of sulphaguanidine with sulphadiazine, an absorbed sulphonamide having less tendency to serious side-effects than sulphapyridine. This showed that sulphadiazine was at least as effective and as well tolerated as sulphaguanidine. This finding seemed to me to provide a way in which an ethically acceptable study of the effects of selected sulphonamides, including a control group receiving no sulphonamide, could be designed.

Having established that sulphadiazine was at least as effective as sulphaguanidine, I thought it justifiable to design a study in which the efficacy of the then accepted standard treatment would be tested against a control group receiving no sulphonamide. The proviso that made it ethically acceptable was that any patient in either group thought to be deteriorating might, after consideration, be given 'open' sulphadiazine, but remain in the study, of course, and included in the final analysis. This study was completed without any great difficulty, as set forth in the 1945 paper. ${ }^{2}$ Its results were no surprise to me, and consistent with my clinical hunches: the effect of sulphonamides in mild to moderate cases of bacillary dysentery was not dramatic, most patients recovering without this allegedly 'specific' treatment. In severer cases there was suggestive evidence of benefit (possibly related to differences in bacterial type), and that the absorbable sulphonamides were more effective than the advocated unabsorbed sulphaguanidine.

During the summer of 1944, in collaboration with the medical officer of the large Infantry Training Depot in our area, I carried out another controlled study. This was completed successfully, and submitted for publication. This study was designed to find out whether prompt administration of sulphaguanidine to men presenting at sick parades with simple diarrhoea might reduce the number who eventually required admission to hospital. In this study, we provided indistinguishable suspensions, one of sulphaguanidine, the other of chalk, which were to be given to alternate men seen at sick parades with mild diarrhoea. The result was unequivocal; the two groups showed no differences, either in the proportions eventually admitted to hospital, or in the hospital course of those admitted.

The story of my efforts to get the second and third papers published may be of some interest. I tell it as objectively as possible, without comment. I completed writing them early in January 1945, and sent them through the usual channels - the local divisional director of medical services, and so on through the hierarchy to London, where, if approved, they would be sent the editors of the journals in which publication had been requested. I sent my paper to the Lancet, and the co-authored paper to the Journal of the Royal Army Medical Corps, since my co-author was a regular officer in Royal Army Medical Corps. At the end of July 1945 , I returned to UK after $41 / 2$ years in the Middle East. I had heard nothing about the fate of the two papers I had submitted more than 6 months previously. When, towards the end of August, I went to see the Consulting Physician to the Army to find out what plans, if any, he had for me, I enquired whether he had seen the papers. He said that he had, and had passed them for publication, and sent for his file relating to them. From this it appeared that they had both been sent to the editor of the Journal of the Royal Army Medical Corps, who had rejected them. I asked the Consulting Physician to the Army whether, as he had approved the papers, I was at liberty to try to get my paper for the Lancet published, and he told me that I could; so I took it straight round to the Lancet's office in Adelphi, where Theodore Fox, the editor, said that if the journal's statistician approved, he would publish it. I'm afraid I lost interest in the other paper, but the manuscript has now been published on the James Lind Library. ${ }^{3}$

\section{REFLECTIONS}

Although I had never been involved in a controlled clinical trial before going to the Middle East, I now realize that very few people at that time ever had. However, I was fully aware of the principles because, before the war, I had attended Bradford Hill's course of lectures, which formed the basis for his book Principles of Medical Statistics. ${ }^{4}$ It was really the application of these principles to clinical practice that was relatively new; the principles had been widely applied in some other biological fields. Looking back, I cannot help reflecting that it was the temporal and local circumstances that made my studies possible. As I have already noted, I was in an area where I had an astonishing degree of autonomy. I was able to take personal responsibility for the design of the studies; there was no requirement to submit everything to an ethics committee.

Although I had, and still have, no ethical qualms about any of them, and having had personal experience of two episodes of bacillary dysentery, would have been perfectly willing to have been included in any of them, I wonder what chance they would have had with a modern research ethics committee! I did not need to apply to anyone for financial support, since the studies were incorporated into the routine activities of the hospital; and, as I had no domestic responsibilities (to my great regret, having been posted abroad in 1941 a few months after my marriage), I 
had no difficulty in finding time for the extra work entailed by the studies.

As regards my motivation in doing these studies, I think I can honestly say that it was simply to find out whether my hunches about the value of an advocated treatment, derived from critical clinical observation, were correct. At that time, I had not heard of Karl Popper-indeed his views on the logic of scientific discovery had been published only in German at that time, and I only much later became aware of them and discovered how consonant they are with my sceptical turn of mind. Now I suppose I might say that having doubts about accepted hypotheses about the value of sulphonamides, especially sulphaguanidine, in dysentery, I wanted to submit them to critical tests.

Another point that these studies illustrate is that in interpreting the practical implications of a controlled or comparative therapeutic trial it is important to remain aware of the criteria on which the type of case studied was defined. Unless unequivocal and precise aetiological definition is possible (which it hardly ever is), there is a danger that among the patients conforming to the definition there are sub-groups with variations in causal factors relevant to outcome. In my studies there was suggestive evidence that response might vary with differences in bacterial type - a hypothesis which could be tested only by a very large and difficult-to-organize study, or by prompt action in an unusual and unpredictable epidemic of dysentery demonstrably caused by single bacillary type.

\section{MEMBERSHIP OF THE MRC STREPTOMYCIN} TRIAL COMMITTEE

I doubt whether my being asked to serve on the MRC Streptomycin Trial committee was in any way related to my having carried out these dysentery studies; indeed, I do not know whether the other members of the committee were aware of them. When I returned to 'civvy street' after the war, my colleagues at the Brompton Hospital elected me Dean of the embryonic Institute of Diseases of the Chest, and I suspect that it was in this capacity that I was asked to join the MRC committee. Nevertheless, I suppose I was one member of that committee who did not need persuading of the importance of as objective a study as possible of the effects of a new drug before it slipped into routine use on the basis of laboratory studies and uncontrolled clinical impressions. The problem of avoiding bias was more difficult than in my studies. Allocation was freed from bias by reference to random sampling numbers. There was no way in which the study could be made 'blind' either to clinicians or to patients; but assessment of the radiographic and some other outcomes could be and were blinded to those making the observations. ${ }^{5}$

A point that is now often not appreciated is that the streptomycin trial illustrates that ethical acceptability is dependent upon local and temporal social and epidemiological circumstances. The accepted management of the many patients with active tuberculosis in 1947 involved long periods of treatment in hospitals and sanatoria, which, in the UK, were part of a publicly financed anti-tuberculosis service. There were long waiting lists for admission to these. This made it possible to arrange that in selected centres, patients with a defined type of pulmonary tuberculosis, thought likely a priori to show detectable change and not thought to be suitable for some accepted procedures, would be admitted without delay and be allocated by random sampling numbers to the best accepted treatment or to accepted treatment with the new drug in addition. All those coming into the trial had much earlier treatment. The supply of streptomycin was limited, and all was being used in the treatment of patients with disease of a kind thought likely to make an initial favourable response, though no-one knew whether, in the long term, this would be outweighed by unforeseen unwanted effects, or at what stage in the possibly long and unpredictable course of the disease it would prove best to use the new drug, whose effects seemed likely at that time to be of limited duration.

Acknowledgments Iain Chalmers and the Journal of the Royal Society of Medicine are grateful to Dr John Scadding for permission to use the photograph of his father.

\section{REFERENCES}

1 Scadding JG. Comparative effects of sulphonamide drugs in mild bacillary dysentery. Lancet 1944;i:784-6

2 Scadding JG. Sulphonamides in bacillary dysentery. Lancet 1945;ii:54953

3 Fletcher RT, Scadding JG. Observations On The M.I. Room Treatment Of "Acute Simple Diarrhoea" With Sulphaguanidine, 1945 [http:// www.jameslindlibrary.org]

4 Hill AB. Principles of Medical Statistics. London: Lancet, 1937

5 Medical Research Council. Streptomycin treatment of pulmonary tuberculosis. BMJ 1948;2:769-82 